\title{
General analytical mass transfer model for VOC emissions from multi-layer dry building materials with internal chemical reactions
}

\author{
WANG XinKe ${ }^{1 *} \&$ ZHANG YinPing ${ }^{2}$ \\ ${ }^{1}$ Department of Building Environment and Services Engineering, Xi'an Jiaotong University, Xi'an 710049, China; \\ ${ }^{2}$ Department of Building Science, Tsinghua University, Beijing 100084, China
}

Received July 25, 2010; accepted September 10, 2010

\begin{abstract}
A general mass transfer based model was developed for analyzing volatile organic compound (VOC) emissions from dry multi-layer building materials with two emission surfaces. This model adds to an earlier multi-layer model by considering chemical reactions within the materials. Consequently, it can be used to analyze the effect of these chemical reactions on removing VOCs, and for characterizing secondary VOC emissions from the building material. The model was validated with literature data and our experimental results. Some typical secondary emissions were analyzed using this model, and obviously differed from the primary emissions. The model is a useful tool for predicting, analyzing and "designing" the VOC emission characteristics, including secondary emissions, of building materials.
\end{abstract}

volatile organic compound, indoor air quality, emissions, building material, mass transfer

Citation: Wang X K, Zhang Y P. General analytical mass transfer model for VOC emissions from multi-layer dry building materials with internal chemical reactions. Chinese Sci Bull, 2011, 56: 222-228, doi: 10.1007/s11434-010-4254-5

Because the majority of people spend most of their time indoors, indoor air quality is of concern [1]. In many buildings without adequate ventilation and with high loads of indoor materials and products, volatile organic compound (VOC) concentrations may be high enough to cause sick building syndrome (SBS). SBS presents with symptoms such as headache, eye, nose, or throat irritation, dry cough, dizziness and nausea, difficulty concentrating, and tiredness [2]. Dry building materials are the main sources of VOCs indoors. Therefore, building material research and industries have focused on control of VOC emissions from building materials and production of low VOC emission materials. The estimation of VOC emissions from dry building materials is also an important issue for many building designers [3]. Models for analyzing VOC emissions from these materials are useful for addressing these problems.

VOC emission models in the literature fall into two general categories [4]: empirical or semi-empirical models

*Corresponding author (email: wangxinke@mail.xjtu.edu.cn)
[5-7], and mass transfer based models [8-27]. The former are often simple and easy to use and their parameters are determined by fitting experimental data to the predefined model. However, they are generally unable to provide mechanistic insight, and it is difficult to scale the results from test conditions to practical conditions. In contrast, mass transfer based models can describe VOC mass transfer mechanisms or processes, and their parameters have clear physical meaning. These models can be used to predict VOC emissions for a wide range of conditions using known physical parameters. The mass transfer model developed by Little et al. [8] is considered the first mass transfer model for analyzing VOC emissions from dry building materials. Many researchers subsequently developed various mass transfer based models to describe more complicated problems, such as emissions from one- [9-15], two- [16], or multi-layer materials [17-21], materials with two emission surfaces [22], and porous materials [23-27]. Secondary VOC emissions from building materials are recognized as an important aspect of indoor VOC exposure [28]. How- 
ever, most studies on secondary emissions have focused on experimental measurements and just one model [23] has been constructed to characterize the behavior of secondary emissions. Unfortunately this model is not suitable for multi-layer building materials, and consequently generalization is limited. Therefore, this paper aimed to develop a general analytical mass transfer model for analyzing the VOC emissions from multi-layer building materials taking into consideration the chemical reactions within the material layers.

\section{Model development}

Typical VOC emission from multi-layer dry building materials occurs as illustrated in Figure 1. The following assumptions are made: (1) all physical properties including the diffusion coefficient and material/air partition coefficient for each layer are constant; (2) mass transfer through the material is one-dimensional; (3) the convective mass transfer coefficients are constant; and (4) the gas phase VOC concentration beyond the concentration boundary layer is uniform.

Transient mass diffusion through the material is governed by the following equation:

$$
\frac{\partial C_{i}}{\partial t}=D_{i} \frac{\partial^{2} C_{i}}{\partial x^{2}}+g_{i}(x, t), t>0, l_{i-1}<x<l_{i},(i=1,2, \cdots N),
$$

where $C_{i}$ is the VOC concentration within the $i$ th layer of the building material, $t$ is the time, $D_{i}$ is the diffusion coefficient of VOC within the $i$ th layer material, $x$ is the coordinate for the thickness, and $g_{i}$ is the chemical reaction rate within the $i$ th layer material.

The boundary conditions are

$$
\begin{gathered}
\dot{m}_{0}(t)=D_{1} \frac{\partial C_{1}}{\partial x}=h_{m, 0}\left(C_{0, s}(t)-C_{0, \infty}(t)\right), \\
t>0, x=l_{0}=0, \\
C_{1}=K_{1} C_{0, s}(t), t>0, x=l_{0}=0,
\end{gathered}
$$

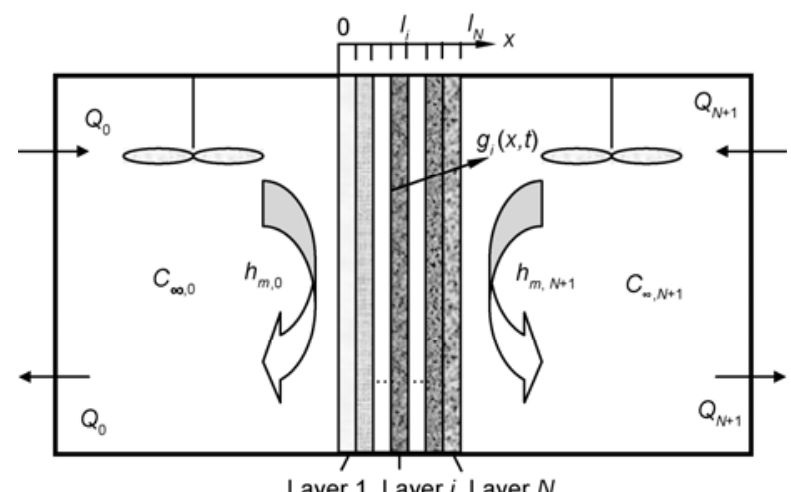

Figure 1 Typical VOC emission from multi-layer dry building materials.

$$
\begin{gathered}
D_{i} \frac{\partial C_{i}}{\partial x}=D_{i+1} \frac{\partial C_{i+1}}{\partial x}, t>0, x=l_{i}, i=1,2, \cdots N-1, \\
\frac{C_{i}}{K_{i}}=\frac{C_{i+1}}{K_{i+1}}, t>0, x=l_{i}, i=1,2, \cdots N-1, \\
\dot{m}_{N+1}(t)=-D_{N} \frac{\partial C_{N}}{\partial x}=h_{m, N+1}\left(C_{N+1, s}(t)-C_{N+1, \infty}(t)\right), \\
t>0, x=l_{N}, \\
C_{N}=K_{N} C_{N+1, s}(t), t>0, x=l_{N},
\end{gathered}
$$

where $\dot{m}_{0}(t)$ and $\dot{m}_{N+1}(t)$ are the emission factors at each emission surface, $h_{m, 0}$ and $h_{m, N+1}$ are the convective mass transfer coefficients at the emission surfaces, $K_{i}$ is the material/air partition coefficient of VOC for the $i$ th layer material, and $C_{0, s}$ and $C_{N+1, s}$ are the gas phase VOC concentrations adjacent to the material surfaces.

The initial condition is given by

$$
C_{0, i}(x)=f_{i}(x), t=0, l_{i-1}<x<l_{i},(i=1,2, \cdots N) .
$$

Separation of variables and Green's function [29] were employed to obtain the solutions to eqs. (1)-(5) as follows:

$$
\begin{aligned}
C_{i}(x, t)= & K_{i}\left[R_{i}(x) C_{0, \infty}(t)+\left(1-R_{i}(x)\right) C_{N+1, \infty}(t)\right] \\
& +\sum_{n=1}^{\infty} \frac{K_{i}}{\beta_{n}^{2} N\left(\beta_{n}\right)} \Psi_{i}\left(\beta_{n}, x\right) \\
& \left\{\left[\begin{array}{l}
\beta_{n}^{2}\left(F\left(\beta_{n}\right)+S\left(\beta_{n}, t\right)\right)- \\
\left.\left(\begin{array}{l}
h_{0} \Psi_{1}\left(\beta_{n}, l_{0}\right) C_{0, \infty}(0)+ \\
h_{N+1} \Psi_{N}\left(\beta_{n}, l_{N}\right) C_{N+1, \infty}(0)
\end{array}\right)\right] \mathrm{e}^{-\beta_{n}^{2} t}
\end{array}\right.\right. \\
& -\left[\begin{array}{l}
t \\
\int^{-\beta_{n}^{2}(t-\tau)} h_{0} \Psi_{1}\left(\beta_{n}, l_{0}\right) \mathrm{d} C_{0, \infty}(\tau)
\end{array}\right. \\
& \left.\left.+\int_{0}^{t} \mathrm{e}^{-\beta_{n}^{2}(t-\tau)} h_{N+1} \Psi_{N}\left(\beta_{n}, l_{N}\right) \mathrm{d} C_{N+1, \infty}(\tau)\right]\right\},
\end{aligned}
$$

where

$$
\begin{gathered}
R_{i}(x)=\frac{h_{0}}{h_{0}+h_{0} h_{N+1} \sum_{j=1}^{N} \frac{l_{j}-l_{j-1}}{K_{j} D_{j}}+h_{N+1}} \\
\left(1+h_{N+1}\left(\frac{l_{i}-x}{K_{i} D_{i}}\right)+\sum_{j=i+1}^{N} \frac{l_{j}-l_{j-1}}{K_{j} D_{j}}\right), \\
l_{i-1}<x<l_{i}, i=1,2, \cdots, N, \\
\sum_{j=i+1}^{N} \frac{l_{j}-l_{j-1}}{K_{j} D_{j}} \equiv 0, \text { when } i=1 \text { or } i=N, \\
N\left(\beta_{n}\right)=\sum_{i=1}^{N} K_{i} \int_{l_{i-1}}^{l_{i}}\left[\Psi_{1}\left(\beta_{n}, x^{\prime}\right)\right]^{2} \mathrm{~d} x^{\prime}, \\
F\left(\beta_{n}\right)=\sum_{i=1}^{N} \int_{l_{i-1}}^{l_{i}} \Psi_{i}\left(\beta_{n}, x^{\prime}\right) f_{i}\left(x^{\prime}\right) \mathrm{d} x^{\prime},
\end{gathered}
$$




$$
\left.\begin{array}{c}
S\left(\beta_{n}, t\right)=\int_{\tau=0}^{t} \mathrm{e}^{\beta_{n}^{2} \tau} \sum_{i=1}^{N} \int_{l_{i-1}}^{l_{i}} \Psi_{i}\left(\beta_{n}, x^{\prime}\right) g_{i}\left(x^{\prime}, \tau\right) \mathrm{d} x^{\prime} \mathrm{d} \tau, \\
\Psi_{i}\left(\beta_{n}, x\right)=A_{i, n} \sin \left(\frac{\beta_{n}}{\sqrt{D_{i}}} x\right)+B_{i, n} \cos \left(\frac{\beta_{n}}{\sqrt{D_{i}}} x\right), \\
l_{i-1}<x<l_{i}, i=1,2, \cdots, N, \\
{\left[\begin{array}{c}
A_{i, n} \\
B_{i, n}
\end{array}\right]=\left(\prod_{j=1}^{i-1} U_{j+1}^{-1}\left(l_{j}\right) U_{j}\left(l_{j}\right)\right)\left[\frac{h_{m, 0}}{\beta_{n} K_{1} \sqrt{D_{1}}}\right],} \\
1
\end{array}\right]
$$

$$
\begin{aligned}
U_{j}(x)= & {\left[\begin{array}{cr}
\sin \left(\frac{\beta_{n}}{\sqrt{D_{j}}} x\right) & \cos \left(\frac{\beta_{n}}{\sqrt{D_{j}}} x\right) \\
K_{j} \sqrt{D_{j}} \cos \left(\frac{\beta_{n}}{\sqrt{D_{j}}} x\right) & -K_{j} \sqrt{D_{j}} \sin \left(\frac{\beta_{n}}{\sqrt{D_{j}} x}\right)
\end{array}\right], } \\
& j=1,2, \cdots, N .
\end{aligned}
$$

When $i=1, \prod_{j=1}^{i-1} U_{j+1}^{-1}\left(l_{j}\right) U_{j}\left(l_{j}\right) \equiv I_{2}=\left[\begin{array}{ll}1 & 0 \\ 0 & 1\end{array}\right]$

$\beta_{n}(n=1,2, \ldots)$ are the positive roots of following transcend equation:

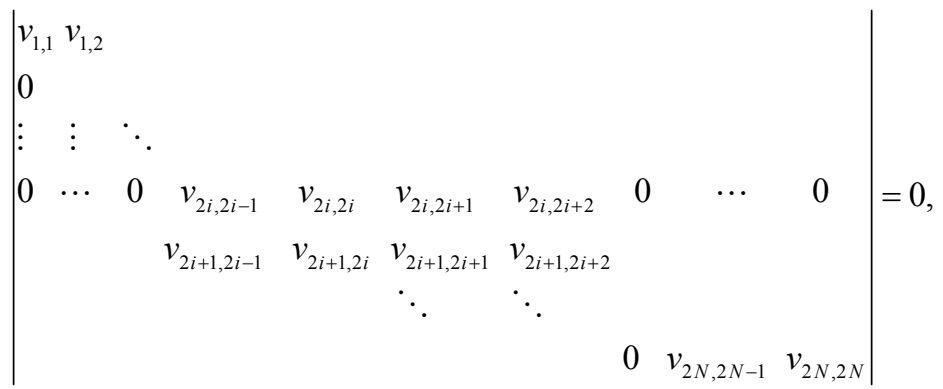

$$
\begin{aligned}
& v_{1,1}=-\beta_{n} K_{1} \sqrt{D_{1}}, v_{1,2}=h_{m, 0} ; v_{2 i, 2 i-1}=\sin \left(\frac{\beta_{n}}{\sqrt{D_{i}}} l_{i}\right), v_{2 i, 2 i}=\cos \left(\frac{\beta_{n}}{\sqrt{D_{i}}} l_{i}\right) \text {, } \\
& v_{2 i, 2 i+1}=-\sin \left(\frac{\beta_{n}}{\sqrt{D_{i+1}}} l_{i}\right), v_{2 i, 2 i+2}=-\cos \left(\frac{\beta_{n}}{\sqrt{D_{i+1}}} l_{i}\right) \text {, } \\
& v_{2 i+2 i-1}=K_{i} \sqrt{D_{i}} \cos \left(\frac{\beta_{n}}{\sqrt{D_{i}}} l_{i}\right), v_{2 i+1,2 i}=-K_{j} \sqrt{D_{i}} \sin \left(\frac{\beta_{n}}{\sqrt{D_{i}}} l_{i}\right) \text {, } \\
& v_{2 i+1,2 i+1}=-K_{i+1} \sqrt{D_{i+1}} \cos \left(\frac{\beta_{n}}{\sqrt{D_{i+1}}} l_{i}\right), v_{2 i+1,2 i+2}=K_{i+1} \sqrt{D_{i+1}} \sin \left(\frac{\beta_{n}}{\sqrt{D_{i+1}}} l_{i}\right),(i=1,2, \cdots, N-1) ; \\
& v_{2 N, 2 N-1}=\beta_{n} K_{N} \sqrt{D_{N}} \cos \left(\frac{\beta_{n}}{\sqrt{D_{N}}} l_{N}\right)+h_{m, N+1} \sin \left(\frac{\beta_{n}}{\sqrt{D_{N}}} l_{N}\right), \\
& v_{2 N, 2 N}=-\beta_{n} K_{N} \sqrt{D_{N}} \sin \left(\frac{\beta_{n}}{\sqrt{D_{N}}} l_{N}\right)+h_{m, N+1} \cos \left(\frac{\beta_{n}}{\sqrt{D_{N}}} l_{N}\right) .
\end{aligned}
$$

Emission factors of both sides can be derived from eqs. (2) and (4) as follows:

$$
\begin{aligned}
\dot{m}_{0}(t)= & -R\left(C_{0, \infty}(t)-C_{N+1, \infty}(t)\right) \\
& +\sum_{n=1}^{\infty} \frac{h_{m, 0}}{\beta_{n}^{2} N\left(\beta_{n}\right)}\left\{\left[\beta_{n}^{2}\left(F\left(\beta_{n}\right)+S\left(\beta_{n}, t\right)\right)\right.\right. \\
& -\left(h_{m, 0} C_{0, \infty}(0)+h_{N+1} \Psi_{N}\left(\beta_{n}, l_{N}\right) C_{N+1, \infty}(0)\right] \mathrm{e}^{-\beta_{n}^{2} t} \\
& -\left[\int_{0}^{t} \mathrm{e}^{-\beta_{n}^{2}(t-\tau)} h_{0} \mathrm{~d} C_{0, \infty}(\tau)\right. \\
& \left.\left.+\int_{0}^{t} \mathrm{e}^{-\beta_{n}^{2}(t-\tau)} h_{N+1} \Psi_{N}\left(\beta_{n}, l_{N}\right) \mathrm{d} C_{N+1, \infty}\right]\right\}
\end{aligned}
$$

$$
\begin{aligned}
\dot{m}_{N+1}(t)= & -R\left(C_{0, \infty}(t)-C_{N+1, \infty}(t)\right) \\
& +\sum_{n=1}^{\infty} \frac{h_{m, N+1}}{\beta_{n}^{2} N\left(\beta_{n}\right)} \Psi_{N}\left(\beta_{n}^{2}, l_{N}\right) \\
& \left\{\left[\beta_{n}^{2}\left(F\left(\beta_{n}\right)+S\left(\beta_{n} t\right)\right)\right.\right. \\
& -\left(h_{0} C_{0, \infty}(0)+h_{N+1} \Psi_{N}\left(\beta_{n}, l_{N}\right) C_{N+1, \infty}(0)\right) \mathrm{e}^{-\beta_{n}^{2} t} \\
& -\left[\int_{0}^{t} \mathrm{e}^{-\beta_{n}^{2}(t-\tau)} h_{0} \mathrm{~d} C_{0, \infty}(\tau)\right. \\
& \left.\left.+\int_{0}^{t} \mathrm{e}^{-\beta_{n}^{2}(t-\tau)} h_{N+1} \Psi_{N}\left(\beta_{n}, l_{N}\right) \mathrm{d} C_{N+1, \infty}(\tau)\right]\right\} .
\end{aligned}
$$

The first term represents the influence of the VOC concen- 
tration difference between two rooms separated by the material. Compared with an earlier model [20], the present model includes a term for the influence of chemical reaction within the building material $\left(S\left(\beta_{n}, t\right)\right)$. The influence of the initial condition (related to $F\left(\beta_{n}\right)$ on the emission characteristics can be easily seen from eqs. (17) and (18), which is an advantage of this method compared with the numerical method. The impact of environmental factors, such as air change rate, volume of the rooms, and emission area, are implied in $C_{i, \infty}$.

Because $C_{i, \infty}$ is unknown, eqs. (17) and (18) are solved combined with the governing equation for indoor VOC concentration (eq. (19)), which is time-discretized to determine the instantaneous indoor VOC concentration.

$$
V_{i} \frac{\mathrm{d} C_{i, \infty}}{\mathrm{d} t}=A_{i} \dot{m}_{i}(t)-Q_{i} C_{i, \infty}, \quad i=0 \text { or } i=N+1,
$$

where $V$ is the volume of the rooms separated by the material, $A$ is the emission area, and $Q$ is the air flow rate.

\section{Validation of the model}

\subsection{Comparison with experimental results for single layer building materials}

Emission testing of single layer dry building materials with two emission surfaces was conducted in an earlier study [30]. The experimental system (Figure 2) included particleboard that was placed in an environmental chamber. Clean air was passed through the chamber, and the outlet air was sampled and the total VOC (TVOC) concentrations were analyzed by gas chromatography. Experimental conditions and parameters for the simulation are listed in Table 1 . The result simulated by the model in the present study was compared with the experimental data of TVOC emissions from dry building materials (Figure 3 ). The calculated correlation coefficient of 0.989 indicates that the model can predict VOC emissions from building material for $>800 \mathrm{~h}$.

\subsection{Validation of the model with an internal chemical reaction}

The model was validated further using a chemical reaction within the building material. This involved placing a clean porous honeycomb ceramic material $(7.99 \mathrm{~cm} \times 8.12 \mathrm{~cm} \times$

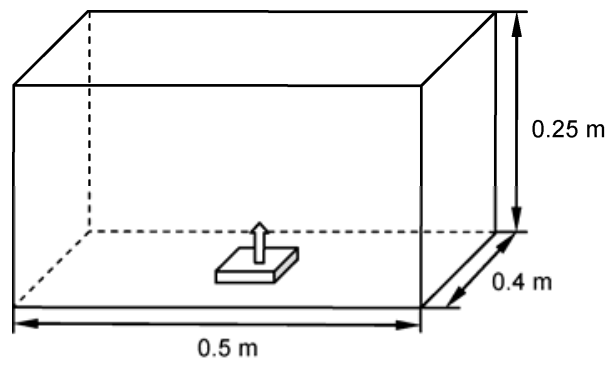

Figure 2 Schematic of the experimental system [30].

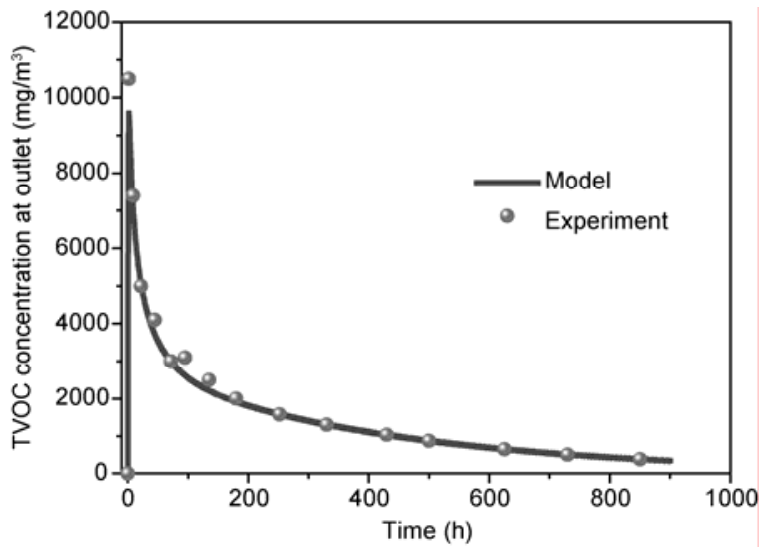

Figure 3 Comparison between the predicted values and the experimental results from [30].

Table 1 The experimental conditions and the parameters used in the simulation in [30]

\begin{tabular}{cc}
\hline Experimental conditions & Parameters \\
\hline Temperature $\left({ }^{\circ} \mathrm{C}\right)$ & $23 \pm 0.5$ \\
Relative humidity $(\%)$ & $50 \pm 0.5$ \\
Air change rate $\left(\mathrm{h}^{-1}\right)$ & $1 \pm 0.05$ \\
Volume of the chamber $(\mathrm{m} \times \mathrm{m} \times \mathrm{m})$ & $0.5 \times 0.4 \times 0.25$ \\
Sizes of the tested particle board $(\mathrm{m} \times \mathrm{m} \times \mathrm{m})$ & $0.212 \times 0.212 \times 0.0159$ \\
$D\left(\mathrm{~m}^{2} / \mathrm{s}\right)$ & $7.65 \times 10^{-11}$ \\
$C_{0}\left(\mu \mathrm{g} / \mathrm{m}^{3}\right)$ & $9.86 \times 10^{7}$ \\
$K$ & 3289 \\
\hline
\end{tabular}

$3.73 \mathrm{~cm}$ ) in an airtight stainless steel chamber (volume $=30$ L) with the air well circulated by a fan (Figure 4). The air velocity was measured by thermal anemometer, and the convective mass transfer coefficient was calculated to be $0.0025 \mathrm{~m} / \mathrm{s}$. Formaldehyde was then injected into the chamber, and its instantaneous concentrations over time were recorded by an Innova gas analyzer (Made by LumaSense Technologies, Inc, Denmark). Because of sorption by the ceramic material, the concentration of formaldehyde in the chamber decayed. An inverse method [31] was employed to fit the chamber concentration into the predicted results from eqs. (18) and (19) without the reaction term to obtain the effective diffusion coefficient $D$ and partition coefficient $K$ of formaldehyde within the material. The regression curve based on eqs. (18) and (19) is shown in Figure 5. The honeycomb ceramic material was then dipped into a liquid containing a thermal catalyst (Macatal Environmental Protection Technology International, Ltd, China). This coated the thermal catalyst on the inner micro-surfaces of the honeycomb ceramic material. The coated material was then placed into the chamber. After injection of formaldehyde, its concentration was measured and found to decay quickly because of the degradation effect of the catalyst. The degradation rate of formaldehyde is expressed as eq. (20):

$$
g(x, t)=-k C(x, t)
$$



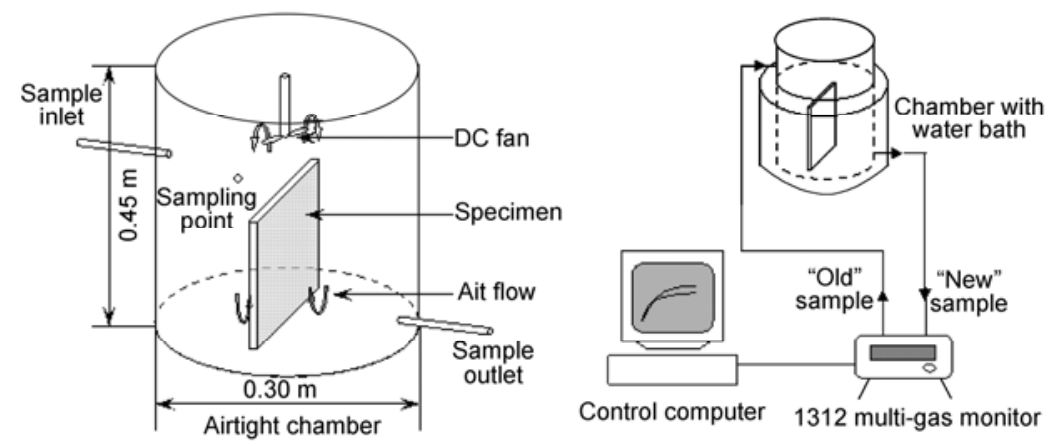

Figure 4 Schematic of the experimental system.

where $k$ is the reaction constant in $\mathrm{s}^{-1}$.

Based on $D$ and $K$ of formaldehyde within the ceramic material, the model with the internal reaction term is used to fit the chamber formaldehyde concentration to obtain the unique unknown parameter, $k$. The regression curve (Figure 6) shows an acceptable agreement between the model and the experimental data. Thus, all parameters for predicting the chamber formaldehyde concentration are available (listed in Table 2).

The material was then removed from the chamber and placed in the ambient atmosphere for about one day to dilute the residual pollutant. Subsequently, it was placed back in the chamber, and formaldehyde was injected into the chamber and its concentration measured. The concentration predicted by the model based on the parameters listed in Table 2 was compared with the measured results (Figure 7). The measured and predicted results agreed, which can be taken as preliminary validation of the model. Deviation between the model and the experimental data may be caused by two factors: (1) the catalyst within the material is not uniformly distributed; and (2) the degradation rate does not adequately satisfy eq. (20).

\section{Example of model application}

Many recent studies have focused on secondary VOC emissions [28]. Secondary VOCs can be generated as follows [32]: (1) from degradation of raw materials, which may take place in linoleum [33,34]; (2) reaction of primary VOCs with ozone or other oxidants, which may occur within porous materials with many large pores; (3) oxidation reactions at the material surface, which has been observed in linoleum [35], PVC flooring [36,37] and carpet [38]; (4) chemical reactions of building materials with substrate material [39]; (5) as microbial VOCs (MVOCs) from mould growth at the bottom of the materials because of dampness [40]; and (6) conversion of immobile VOCs to mobile VOC under certain conditions [41]. Reaction rates in for these six types of secondary VOC emission are relatively stable because the amount of reactant changes slowly. Therefore, we
Table 2 Parameters used in the prediction of the chamber formaldehyde concentration

\begin{tabular}{cc}
\hline Parameters & Value \\
\hline Volume of the chamber $\left(\mathrm{m}^{3}\right)$ & 0.03 \\
Size of the tested material $(\mathrm{cm} \times \mathrm{cm} \times \mathrm{cm})$ & $7.99 \times 8.12 \times 3.73$ \\
$D\left(\mathrm{~m}^{2} / \mathrm{s}\right)$ & $1.23 \times 10^{-11}$ \\
$C_{0}\left(\mathrm{mg} / \mathrm{m}^{3}\right)$ & 0.00 \\
$\mathrm{~K}$ & 1341 \\
$k\left(\mathrm{~s}^{-1}\right)$ & 12 \\
$h_{m}(\mathrm{~m} / \mathrm{s})$ & 0.0025 \\
\hline
\end{tabular}

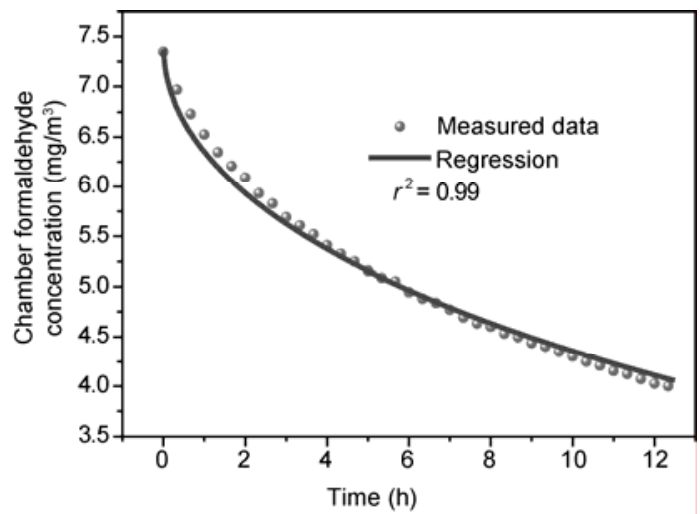

Figure 5 Regression of $K$ and $D$ of formaldehyde with the material $\left(K=1341, D=1.23 \times 10^{-11} \mathrm{~m}^{2} / \mathrm{s}, C_{0}=0 \mathrm{mg} / \mathrm{m}^{3}\right)$.

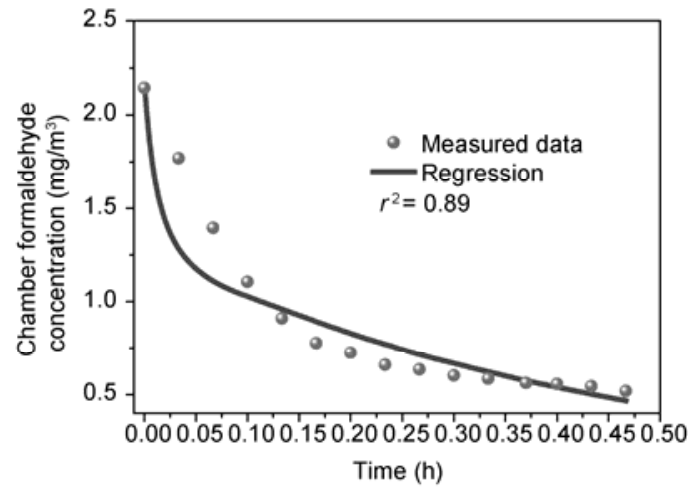

Figure 6 Regression of formaldehyde degradation constant $k$ of the material with thermal catalyst $\left(k=12 \mathrm{~s}^{-1}\right)$. 


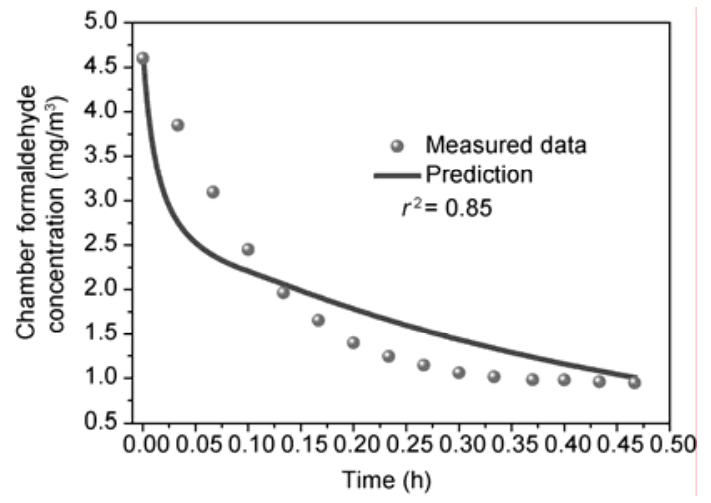

Figure 7 Comparison between the measured data and that predicted by the model.

only evaluated secondary emissions with constant reaction rates for the following three cases: (a) reactions throughout the material, (b) reaction at the surface, and (c) reaction at the bottom. For each of these three cases, building materials with different secondary VOC sources were placed in the chamber. The properties of the building materials and chamber parameters are listed in Table 1. The ratio of emission factor to the product of reaction rate and thickness of reaction layer was used to obtain a normalized emission factor (Figure 8) for each of the three cases. Primary emission was not considered for simplification, that is, the initial VOC concentration $C_{0}$ was zero. The emission factors increased with time in all cases, which is very different from primary emissions. In addition, all of the normalized emission factors were $<1$, which indicates the emission factor was not higher than the product of reaction rate and thickness of the reaction layer. Large differences observed among the three cases can be understood by considering VOC diffusion within the materials. When the reaction takes place on the surface of the material (case (b)), the normalized emission factor is highest because nearly all the generated VOCs are emitted into the ambient air immediately. When the reaction occurs throughout the material (case (a)) the lower normalized emission factor is lower than in case

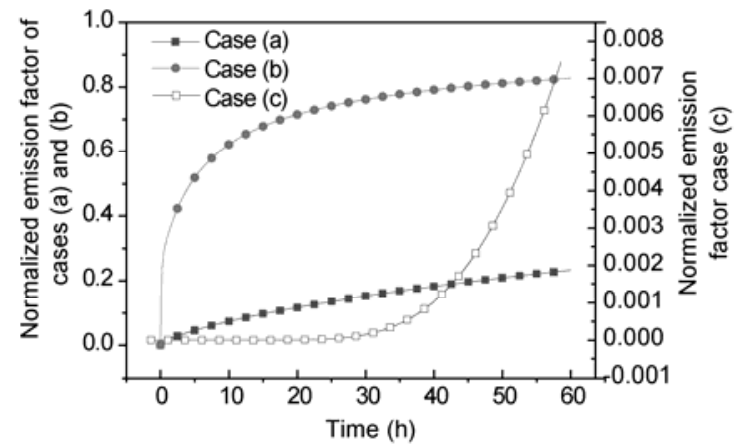

Figure 8 Comparison between different secondary VOC sources. Case (a): constant reaction rate throughout the whole material. Case (b): constant reaction rate at the surface of the material. Case (c): constant reaction rate at the bottom of the material. (b) because the VOCs generated within the material have to diffuse to the surface before they are emitted. Case (c) produces the lowest normalized emission factor because all generated VOCs must penetrate through the entire thickness of the material first and the normalized emission factor is zero before the VOCs from the bottom reach the surface. These results are consistent with those obtained by Lee et al. [25].

From Figure 8, it can be seen that the emission rate with only secondary VOC sources is low initially, while according to an earlier study [13] the emission rate with only primary sources decreases with time. Therefore, when primary and secondary emissions both occur, primary emission features early on and secondary emission is dominant at a later stage. To illustrate the difference between primary emission and secondary emission, the emission factors for primary and secondary emission together and primary emission alone were simulated (Figure 9) using the parameters in Table 1. The reaction related to secondary emission took place throughout the material with a constant reaction rate $1000 \mu \mathrm{g} \mathrm{m}^{-3} \mathrm{~s}^{-1}$. Over time the emission factor increased because of secondary emission. These results suggest that evaluation of primary emissions alone cannot be used to assess VOC emission characteristics from building materials with internal chemical reactions.

\section{Conclusions}

The proposed model can be used to predict, analyze and "design" VOC emissions from multi-layer dry building materials with internal chemical reactions. Compared with numerical methods, the proposed analytical model conveniently provides insight into how the initial VOC concentration, internal chemical reactions, and ambient gas VOC concentration affect the VOC emission. This model was validated using literature experimental data and our experiments. Further validation is required, especially for materials in which internal chemical reactions occur. This model was used to analyze the characteristics of typical secondary VOC

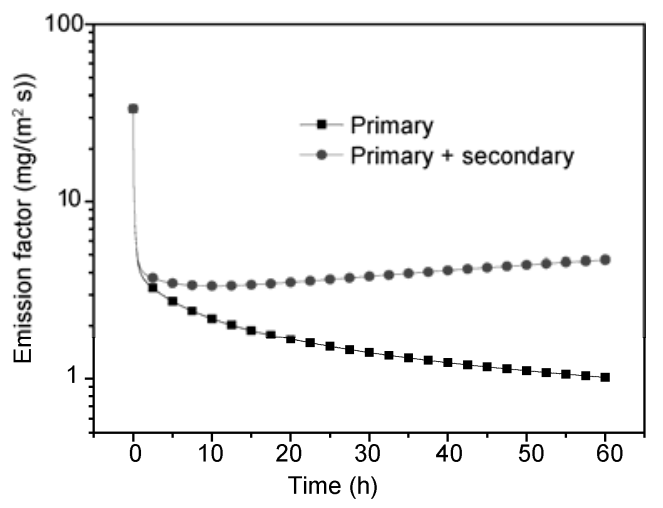

Figure 9 Comparison of primary emission alone and in combination with secondary emission. 
emissions, and showed that they were obviously different from those of primary emissions.

This work was supported by the National Natural Foundation of China (50725620) and the Chinese National Eleventh Five-years Plan Project (2006BAJ02A08).

1 Klepeis N E, Nelson W C, Ott W R, et al. The National Human Activity Pattern Survey (NHAPS): A resource for assessing exposure to environmental pollutants. J Expos Anal Environ Epidemiol, 2001, 11: 231-252

2 Molhave L. The sick buildings and other buildings with indoor climate problems. Environ Inter, 1989, 15: 65-74

$3 \mathrm{Yu} \mathrm{C}$, Crump D. A review of the emission of VOCs from polymeric materials used in buildings. Build Environ, 1998, 33: 357-374

4 Guo Z. Review of indoor emission source models, Part 1: Overview. Environ Pollut, 2002, 120: 533-549

5 Hoetjer J J, Koerts F. A model for formaldehyde release from particleboard. In: Meyer B, Andrews B A, Reinhardt R M, eds. Formaldehyde release from wood products. Am Chem Soc. Washington DC, 1986, 125-144

6 Dunn L E. Models and statistical methods for gaseous emission testing of finite sources in well-mixed chambers. Atmos Environ, 1987, 21: $425-430$

7 ASTM Standard D5116-97, Standard guide for small-scale environmental chamber determinations of organic emissions from indoor materials/products. Am Soc Testing Materials, Philadelphia, PA., 1997

8 Little J C, Hodgson A T, Gadgil A J. Modeling emissions of volatile organic-compounds from New Carpets. Atmos Environ, 1994, 28: 227-234

9 Yang X, Chen Q, Zhang J S, et al. Numerical simulation of VOC emissions from dry materials. Build Environ, 2001, 36: 1099-1107

10 Cox S S, Little J C, Hodgson A T. Predicting the emission rate of volatile organic compounds from vinyl flooring. Environ Sci Technol, 2002, 36: 709-714

11 Huang H Y, Haghighat F. Modeling of volatile organic compounds emission from dry building materials. Build Environ, 2002, 37: 11271138

12 Kumar D, Little J C. Single-layer model to predict the source/sink behavior of diffusion-controlled building materials. Environ Sci Technol, 2003, 37: 3821-3827

13 Xu Y, Zhang Y P. An improved mass transfer based model for analyzing VOC emissions from building materials. Atmos Environ, 2003, 37: 2497-2505

14 Deng B Q, Kim C N. An analytical model for VOCs emission from dry building materials. Atmos Environ, 2004, 38: 1173-1180

$15 \mathrm{Xu} \mathrm{Y,} \mathrm{Zhang} \mathrm{Y} \mathrm{P.} \mathrm{A} \mathrm{general} \mathrm{model} \mathrm{for} \mathrm{analyzing} \mathrm{single} \mathrm{surface} \mathrm{VOC}$ emission characteristics from building materials and its application. Atmos Environ, 2004, 38: 113-119

16 Kumar D, Little J C. Characterizing the source/sink behavior of double-layer building materials. Atmos Environ, 2003, 37: 5529-5537

17 Haghighat F, Huang H Y. Integrated IAQ model for prediction of VOC emissions from building material. Build Environ, 2003, 38: 1007-1017

18 Zhang L Z, Niu J L. Modeling VOCs emissions in a room with a single-zone multi-component multi-layer technique. Build Environ, 2004, 39: 523-531

19 Yuan H L, Little J C, Marand E, et al. Using fugacity to predict volatile emissions from layered materials with a clay/polymer diffusion barrier. Atmos Environ, 2007, 41: 9300-9308

20 Hu H P, Zhang Y P, Wang X K, et al. An analytical mass transfer model for predicting VOC emissions from multi-layered building materials with convective surfaces on both sides. Inter J Heat Mass
Transfer, 2007, 50: 2069-2077

21 Li F, Niu J L. Control of volatile organic compounds indoors: Development of an integrated mass-transfer-based model and its application. Atmos Environ, 2007, 41: 2344-2354

22 Wang X K, Zhang Y P, Zhao R Y. Study on characteristics of double surface VOC emissions from dry flat-plate building materials. Chinese Sci Bull, 2006, 51: 2287-2293

23 Lee C S. A theoretical study on VOC source and sink behavior of porous building materials. Dissertation for the Doctoral Degree. Montreal, Canada: Concordia University, 2003

24 Haghighat F, Huang H Y, Lee C S. Modeling approaches for indoor air VOC emissions from dry building materials-A review, ASHRAE Transaction, 2005: 635-645

25 Lee C S, Haghighat F, Ghaly W S. A study on VOC source and sink behavior in porous building materials-analytical model development and assessment. Indoor Air, 2005, 15: 183-196

26 Xiong J Y, Zhang Y P, Wang X K. Macro-meso two-scale model for predicting the VOC diffusion coefficients and emission characteristics of porous building materials. Atmos Environ, 2008, 42: 5278-5290

27 Shen X Z, Chen Z Q. Coupled heat and formaldehyde migration in dry porous building materials. Build Environ, 2010, 45: 1470-1476

28 Charles W, Tunga S. Forum 10-Recent advances in indoor chemistry. Summary Report of Indoor Air 2005 Forums, 2005, Sept. 4-9, Beijing, 23-25

29 Ozisik M N. Heat Conduction. New York: John Wiley and Sons Press, 1980. 294-323

30 Yang X. Study of building material emissions and indoor air quality. Dissertation for the Doctoral Degree. Massachusetts: Massachusetts Institute of Technology, 1999

31 Li F, Niu J L. An inverse technique to determine volatile organic compounds diffusion and partition coefficients in dry building material. Inter J Heat Mass Transfer, 2005, 41: 834-842

32 Lee C S, Haghighat F, Ghaly W S. Modeling the VOC emissions of solid/wet building material assembly and its assessment. In: Proceedings of the 9th International Conference on Indoor Air Quality and Climate, 2002, June 30 - July 5, Monterey, California. Vol. 3: 238-243

33 Jensen B, Wolkoff P, Wilkins C K, et al. Characterization of linoleum .1. measurement of volatile organic compounds by use of the field and laboratory emission cell. Indoor Air, 1995, 5: 38-43

34 Wolkoff P. Volatile organic compounds-Sources, measurements, emissions, and the impact on indoor air quality. Indoor Air, 1995, 5: 1-73

35 Jensen B, Wolkoff P, Wilkins C K. Characterization of linoleum identification of oxidative emission processes. In: Tichenor B A, ed. Characterizing Sources of Indoor Air Pollution and Related Sink Effects, ASTM STP-1287, 1996, 145-152

36 Knudsen H N, Kjaer U D, Nielsen P A, et al. Sensory and chemical characterization of VOC emissions from building products: Impact of concentration and air velocity. Atmos Environ, 1999, 33: 1217-1230

37 Wolkoff P. Impact of air velocity, temperature, humidity and air on long term VOC emissions from building products. Atmos Environ, 1998, 32: 2659-2668

38 Weschler C J, Hodgson A T, Wooley J D. Indoor chemistry: Ozone, volatile organic compounds, and carpets. Environ Sci Technol, 1992, 26: $2371-2377$

39 Rothweiler H, Mengon W, Meier G, et al. Emissions of degradation products of building materials in the indoor environment-Case studies, in: Proceedings of Indoor Air 93, 1993, July 4-8 Helsinki, Finland. Vol. 2: 465-470

40 Bjurman J. Release of MVOCs from microorganisms. In: Salthammer T, ed. Organic Indoor Air Pollutants: Occurrence, Measurement, Evaluation. New York: Wiley-VCH. 1999. 259-273

41 Cox S S, Hodgson A T, Little J C. Measuring concentrations of volatile organic compounds in vinyl flooring. J Air Waste Manage Assoc, 2001, 51: 1195-1201

Open Access This article is distributed under the terms of the Creative Commons Attribution License which permits any use, distribution, and reproduction in any medium, provided the original author(s) and source are credited. 